\title{
Wind Power Plants Protection Using Overcurrent Relays
}

\author{
Nima Rezaei ${ }^{1,2, *}$, Mohammad Lutfi Othman ${ }^{1,2}$, Noor Izzri Abdul Wahab ${ }^{1,2}$, Hashim Hizam ${ }^{1,2}$, \\ Osaji Emmanuel Olufemi ${ }^{1,2}$
}

\author{
${ }^{1}$ Department of Electrical \& Electronic Engineering, University Putra Malaysia, Serdang, 43400, Selangor, Malaysia \\ ${ }^{2}$ Centre of Advanced Power and Energy Research (CAPER), University Putra Malaysia, 43400, Selangor, Malaysia \\ *Corresponding Author: nima_rezaei_69@yahoo.com
}

Copyright (C) 2014 Horizon Research Publishing All rights reserved.

\begin{abstract}
Wind power plants are one of the most crucial types of renewable energies which are increasingly employed in smart grids with purpose of power generation especially as a distribution generation system. Hence, the proper protection of wind plants is an enormously significant aspect which must be taken into consideration when designing the wind plants to not only provide a suitable protection for the power components but also maintain the power generation perpetually in case of fault. The most important and common protection systems are overcurrent relays which can protect the power systems from impending faults. In order to implement a successful and proper protection for wind power plants, these relays must be set accurately and well coordinated with each other to clear the fault at the system in the shortest possible time. This paper demonstrates how the coordination of overcurrent relays can be successfully achieved in wind power plants in order to maintain the power generation during fault and protect the power components.
\end{abstract}

Keywords Overcurrent Relay, Coordination of Overcurrent Relay, Wind Power Plant, Power System Protection

\section{Introduction}

The ever increasingly air pollution rate and the limitation of fossil fuel sources have led to comprehensive implementation of renewable energies specifically wind energy [1]. Wind power plants have been vastly employed as the means of power generation in smart grids as a distribution generation (DG) system [2]. One of the most important studies of power quality and power system protection in wind plants is proving adequate and continual power to the loads, therefore in order to ensure having perpetual power from wind farms, wind plants must feed grids continually [3].

One way of meeting this phenomena is applying a proper protection in the system that in case of fault, only the section of faulty feeder is disconnected from the system and the rest of healthy parts are kept connected to the system [4]. By using overcurrent relays (OCRs) as a protection system and applying an accurate coordination in wind plants, not only in case of fault, the power components are protected from damages from excessive currents but also continual power flow is fed to the grid and superb power quality is provided by wind power plants [5].

This paper demonstrates how OCRs have been successfully used and properly coordinated in a wind power plant. The software which has been used is Matlab/Simulink. All of the OCRs have been modelled and designed and the accurate settings have been selected to protect the wind plant.

\section{Overcurrent Relay}

OCRs have the same basic I/O signal operation as other types of relays. In these relays, if the incoming current is higher than the preset current value, the relay will send out an output signal to the circuit breaker (CB) to disconnect the circuit in order to protect the power components from the result of current excess [6]. There are three main types of OCRs used in power systems, which are: definite current relay, definite time relay and inverse time relay [7]. The most common type is inverse time relay which has an inverse curve characteristic. This curve defines the operation of the relay which functions in a faster time as the current increases. These types of relays are usually included with an instantaneous unit which causes the relay to operate instantaneously when the current reaches a high limit magnitude thus eliminating the damage to the power components.

Inverse time OCRs based on their sensitivity to the current and time can have several characteristics which is reliant on the application. These OCRs types, according to IEC standard are depicted in table 1. Below. 
Table 1. Different Characteristic of OCRs

\begin{tabular}{|c|c|}
\hline Type of OCR & Operation time \\
\hline Normally Inverse & $\mathrm{T}=\frac{0.14 * \mathrm{TSM}}{\left(\frac{\mathrm{I}}{\text { Tpickup }}\right)^{0.02-1}}$ \\
\hline Very Inverse & $\mathrm{T}=\frac{13.5 * \mathrm{TSM}}{\left(\frac{\mathrm{I}}{\text { Tpickup }}\right)^{1}-1}$ \\
\hline Extremely Inverse & $\mathrm{T}=\frac{80 * \mathrm{TSM}}{\left(\frac{\mathrm{I}}{\text { Ipickup }}\right)^{2}-1}$ \\
\hline Long Time Inverse & $\mathrm{T}=\frac{120 * \mathrm{TSM}}{\left(\frac{I}{\text { Ipickup }}\right)^{1-1}}$ \\
\hline
\end{tabular}

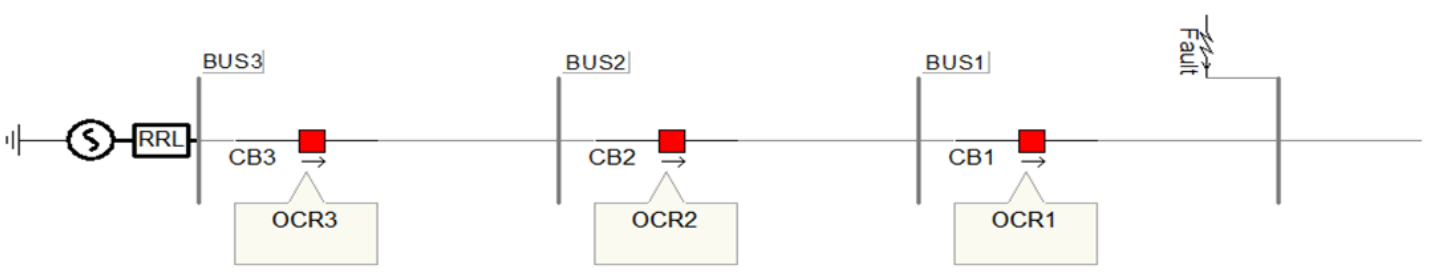

Figure 1. The Concept of OCRs Coordination

In power systems, all of these OCRs must be properly coordinated with each other in order to protect the power elements from the currents [8]. To do so, the vital settings of OCRs, which are the Plug Setting Multiplier (PSM) and the Time Setting Multiplier (TSM), must be set suitably. PSM is varied in the range of $50 \%$ to $200 \%$ and in steps of $25 \%$ [9]. This setting is only used for inverse current relays which detect phase to phase fault. For the relays that detect phase to ground fault, the PSM is quite different. It is varied in in the range of $10 \%$ to $40 \%$ in steps of $10 \%$, or in the range of $20 \%$ to $80 \%$ in steps of $20 \%$. The point that should be taken into consideration is that the more Plug Setting (PS) the relay has, the higher current the relay requires to trip. TSM ranges from 0 to 1 in steps of 0.1 . However, sometimes it varies in steps of 0.05. The maximum TSM is 1 and the minimum is 0.05 . In order to coordinate OCRs with each other, there is a time interval between a primary relay and a backup relay operation and this is called the Coordination Time Interval (CTI). This time interval is in the range of 0.3 and 0.5 seconds for conventional relays, while for numerical relays it is set at 0.2 seconds, which means they operate faster compared to conventional relays [10]. So in order to coordinate relays with each other, the relay operation time and CTI must be taken into consideration. After the characteristics of these relays are designated, then the coordination of OCRs can be properly undertaken [11].

Coordination of OCRs basically means that the closest relay to the fault location, which is referred to as the primary relay, must first trip the $\mathrm{CB}$, and in case the relay does not trip or malfunctions, the other relay closest to the primary relay, which is called the backup relay, must trip. This coordination is extremely crucial and is conducted in order to decrease the expanded power loss and avert power quality compromise. The coordination phenomenon is depicted in Fig 1. In this figure, OCR1 as primary protection must trip to the fault. In case of any malfunction, OCR2 as backup protection should trip. Also if OCR2 does not operate, OCR3 as the second backup protection must trip and disconnect the feeder.

\section{Simulation Results for OCRs Coordination in a Wind Plant}

Matlab/Simulink as a powerful software has been used to model the wind plant, relays, set the relay settings and coordinate them well with each other. A typical wind power plant has been modelled in this paper and based on the load flow, OCRs using IEC standard has been designed, set and coordinated.

The wind power plant modelled in this paper, consists of 5 wind turbines that each of them produce $2 \mathrm{MW}$. Their voltage and frequency are $575 \mathrm{~V}$ and $60 \mathrm{~Hz}$ respectively. Transformers corresponding to each wind turbine has voltage ratio of $575 \mathrm{~V} / 25 \mathrm{KV}$ in star delta configuration where the star side is earthed. The last Transformer corresponding to the grid has the voltage ratio of $25 \mathrm{KV} / 110 \mathrm{KV}$ and delta star configuration where star is earthed. The transmission lines have $10 \mathrm{Km}$ length each. The wind power plant model is illustrated in Fig 2. In this figure, since the protection area is the main scope of this paper, the breakers have been highlighted as orange colour named by CB1, CB2 ... CB12 and the corresponding relays to each breakers, are highlighted as red colour shown by R1, R2 ... R12. 
In order to set the relays and properly coordinate them, the exact value of current and short circuit current flowing through each CB should be derived. Fig 3. To Fig 6. Depicts the characteristic of current in Amper unit at each CB before, during and after fault. In this simulation, the total simulation time is $50 \mathrm{~s}$. A three phase fault has been imposed to each breaker at time 25 lasting for $5 \mathrm{~s}$.

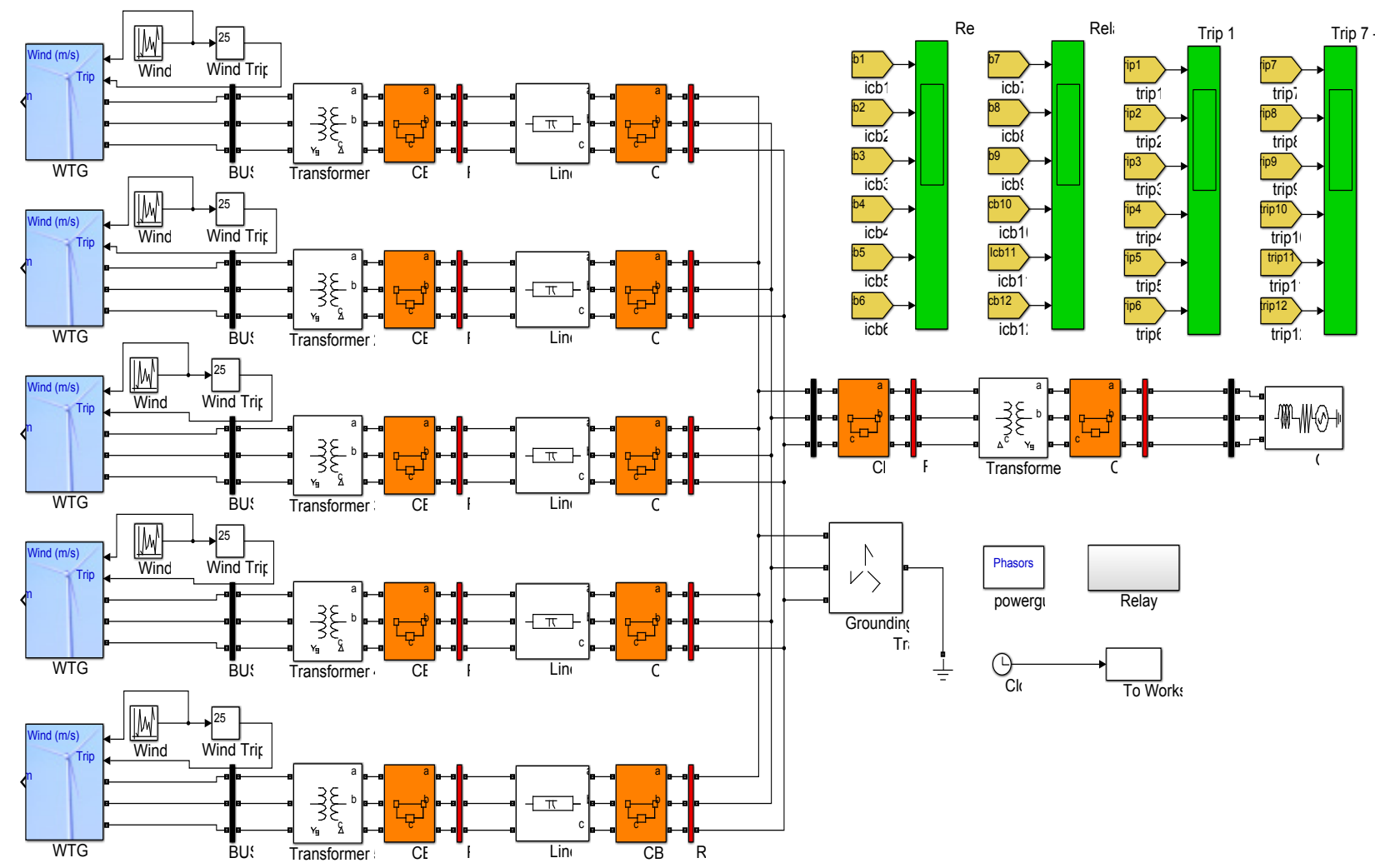

Figure 2. Simulink Model for Wind Power Plant

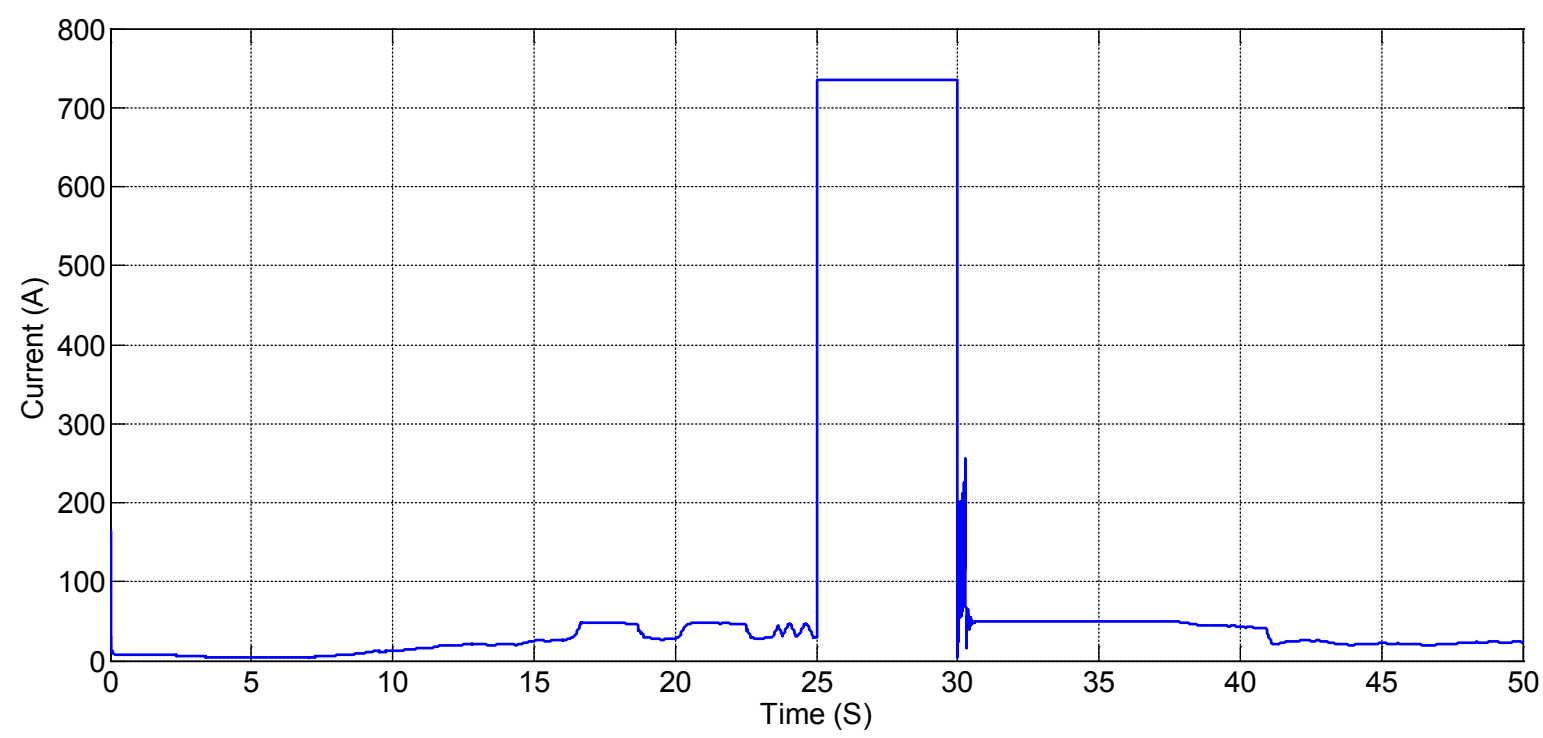

Figure 3. Load Flow through CB12 during Fault 


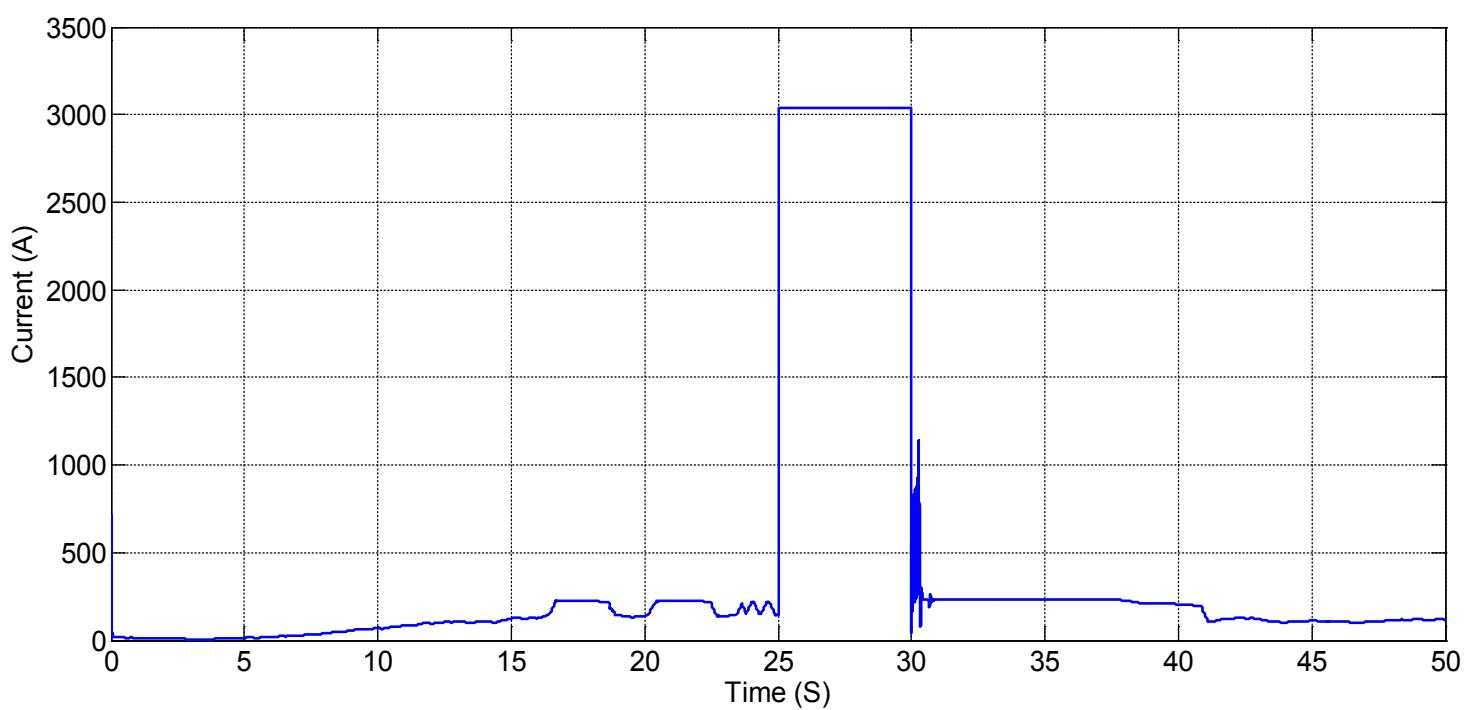

Figure 4. Load Flow through CB11 during Fault

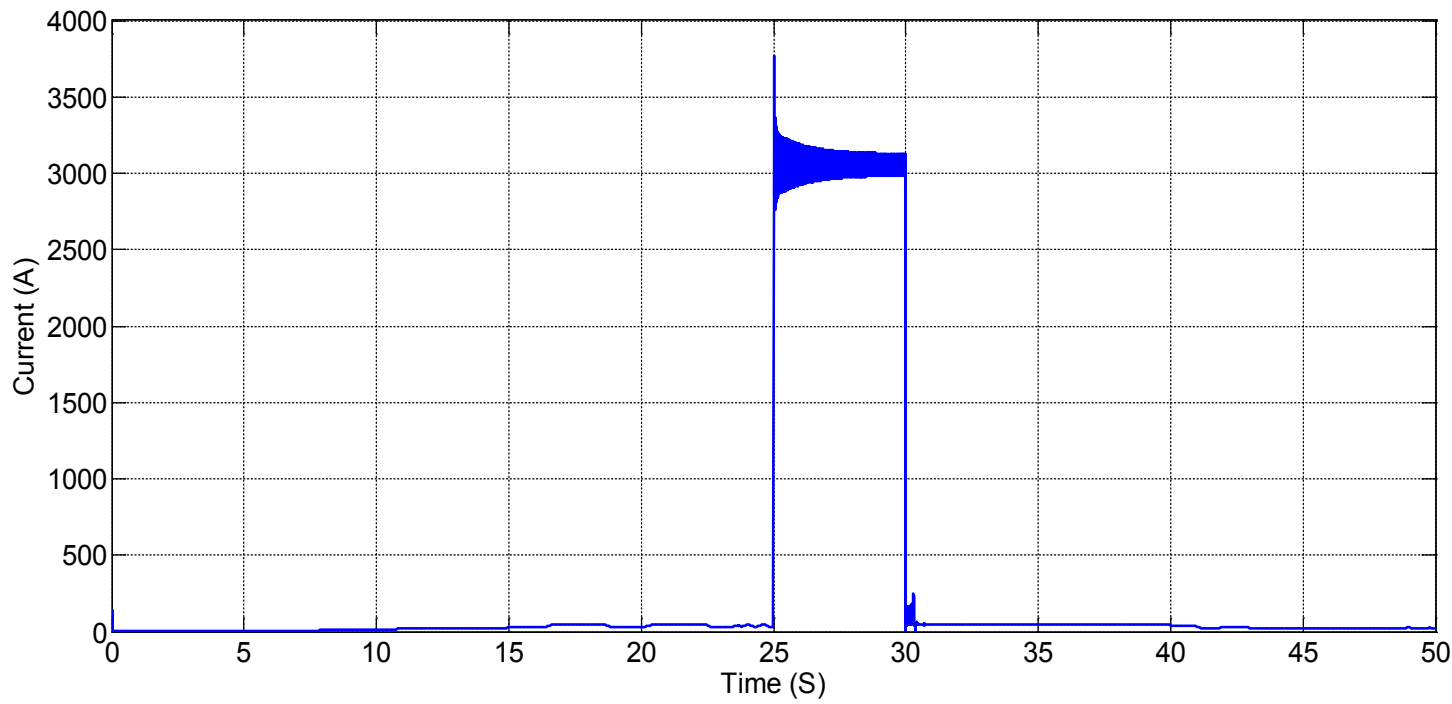

Figure 5. Load Flow through CB2 during Fault

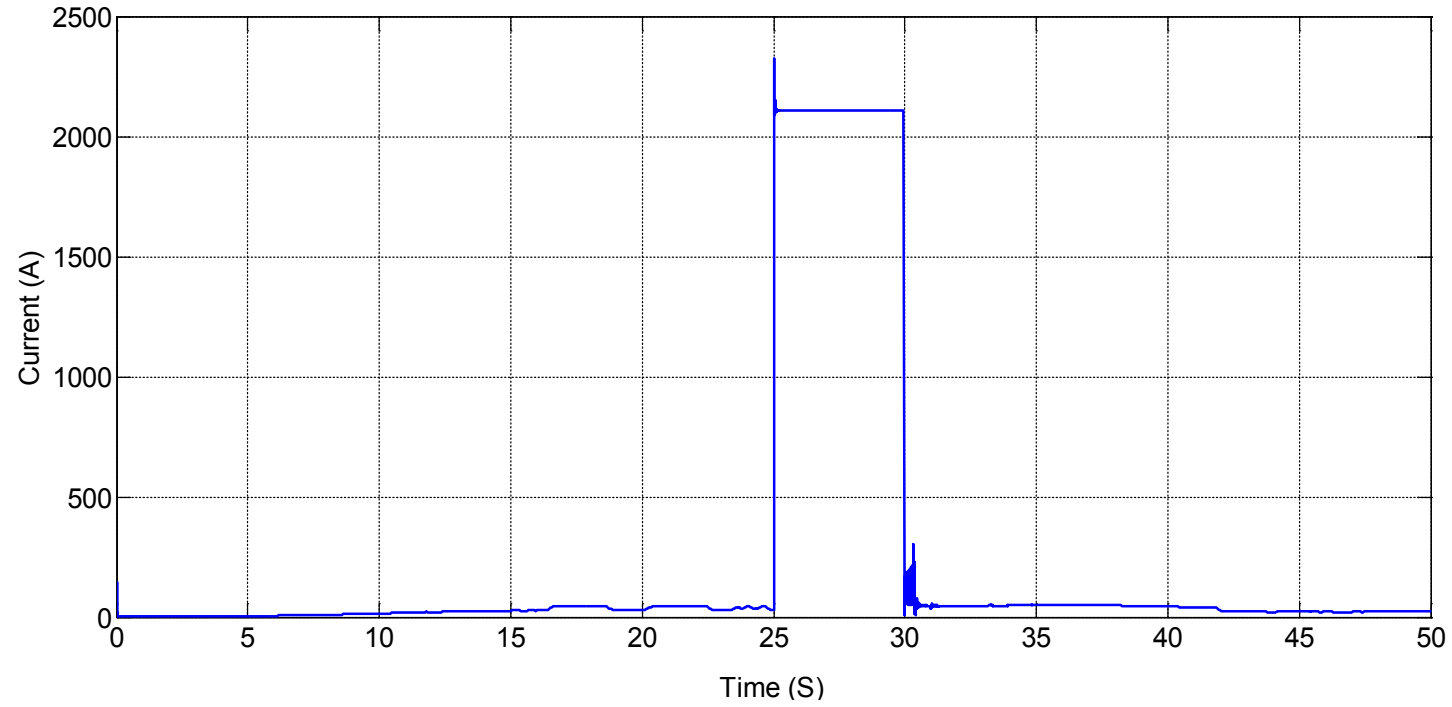

Figure 6. Load Flow through CB1 during Fault 
As it can be seen from the simulation, at time 25 , when a three phase fault is imposed to the system, current is increased abundantly and voltage dips drastically which can damage the power systems and compromise the power quality. Therefore a proper protection must be employed to prevent this catastrophe. In this paper OCRs as the best protection relay in wind power plants have been implemented and the results in the next section have affirmed its prosperity, effectiveness and accuracy.

\section{Results and Discussion}

After getting the required data for setting the relays, including exact value of load current and short circuit current at each CB, OCRs can then be modelled, set and coordinated. In order to get the best results with purpose of relays coordination, the exact value of short circuit current located near each $\mathrm{CB}$ should be extracted and based on the maximum load current, relays can be set.

The results below demonstrates that relays have been successfully set and are well coordinated with each other. CTI has been opted as to be $0.4 \mathrm{~s}$ and normal inverse relay has been chosen in this simulation. Fig 7. To Fig 10. Illustrates the relays behaviour at each fault occurred from time 25 to 30.Fig12.To Fig15.DepictstheCBsoperation corresponding the each relays.

As an example, when there is fault near CB12, relay 12 must detect the fault and send the proper tripping signal to the CB12 to disconnect the system until the fault is cleared. As it is clear in the pictures, relay12 trips at time 25.15 and the CB12 has disconnected the feeder exactly at 25.15 which shows the relay and CB are working well.

The other scenario that must be taken into consideration is that in case relay 12 has not tripped and malfunctioned, the closest relay to relay 12 which is relay11 must trip after a specific delay time which is known as CTI. In Fig 11. This phenomena is shown. Since the CTI is set to be as $0.4 \mathrm{~s}$, then as it is expected, relay 11 must trip and command the CB11 to disconnect the feeder at time 25.55.

This procedures have been tested for all of the faults at each CB and the results of relay settings, have been compiled in Table 2. In this table all of the current measurements are in Amper unit. $\mathrm{I}_{\text {pickup }}$ and $\mathrm{I}_{\text {pickup relay }}$ refers to the minimum magnitude of current that the relay trips before and after the Current Transformer (CT) respectively. The fourth column represent the CT ratio at each relay. PS, PSM and TSM corresponds to the relay settings that describes how each relay has been set and behaves in case of fault. The last column illustrates $\mathrm{T}$ that is the amount of delay time that the relay trips. One thing that should be taken into consideration is that since all of the 5 wind turbine feeders have the same current characteristics, therefore relay settings for relays 1, 3, 5, 7 and 9 are the same. Also the relay setting for relays2, 4, 6, 8 and 10 are the same as each other too.

Through the simulation results it is resulted that relays have been set accurately and are well coordinated with each other in order to protect the wind power plant. Thus OCRs can be considered as one of the best and most successful technique of protection for wind farms.

Table 2. OCRs Settings for the Wind Power Plant

\begin{tabular}{|c|c|c|c|c|c|c|c|}
\hline Relay & $\mathrm{I}_{\text {pickup }}$ & $\mathrm{I}_{\text {pickup relay }}$ & $\mathrm{CT}$ & $\mathrm{PS}$ & PSM & TSM & $\mathrm{T}$ \\
\hline $\mathrm{R} 1$ & 75 & 3.75 & $100: 5$ & $75 \%$ & 50.25 & 0.80 & 1.35 \\
\hline $\mathrm{R} 2$ & 62.5 & 6.25 & $50: 5$ & $125 \%$ & 9.72 & 0.35 & 0.95 \\
\hline $\mathrm{R} 3$ & 75 & 3.75 & $100: 5$ & $75 \%$ & 50.25 & 0.80 & 1.35 \\
\hline $\mathrm{R} 4$ & 62.5 & 6.25 & $50: 5$ & $125 \%$ & 9.72 & 0.35 & 0.95 \\
\hline $\mathrm{R} 5$ & 75 & 3.75 & $100: 5$ & $75 \%$ & 50.25 & 0.80 & 1.35 \\
\hline $\mathrm{R} 6$ & 62.5 & 6.25 & $50: 5$ & $125 \%$ & 9.72 & 0.35 & 0.95 \\
\hline $\mathrm{R} 7$ & 75 & 3.75 & $100: 5$ & $75 \%$ & 50.25 & 0.80 & 1.35 \\
\hline $\mathrm{R} 8$ & 62.5 & 6.25 & $50: 5$ & $125 \%$ & 9.72 & 0.35 & 0.95 \\
\hline $\mathrm{R} 9$ & 75 & 3.75 & $100: 5$ & $75 \%$ & 50.25 & 0.80 & 1.35 \\
\hline $\mathrm{R} 10$ & 62.5 & 6.25 & $50: 5$ & $125 \%$ & 9.72 & 0.35 & 0.95 \\
\hline $\mathrm{R} 11$ & 312.5 & 6.25 & $250: 5$ & $125 \%$ & 2.35 & 0.1 & 0.55 \\
\hline $\mathrm{R} 12$ & 75 & 3.75 & $100: 5$ & $75 \%$ & 9.79 & 0.05 & 0.15 \\
\hline
\end{tabular}




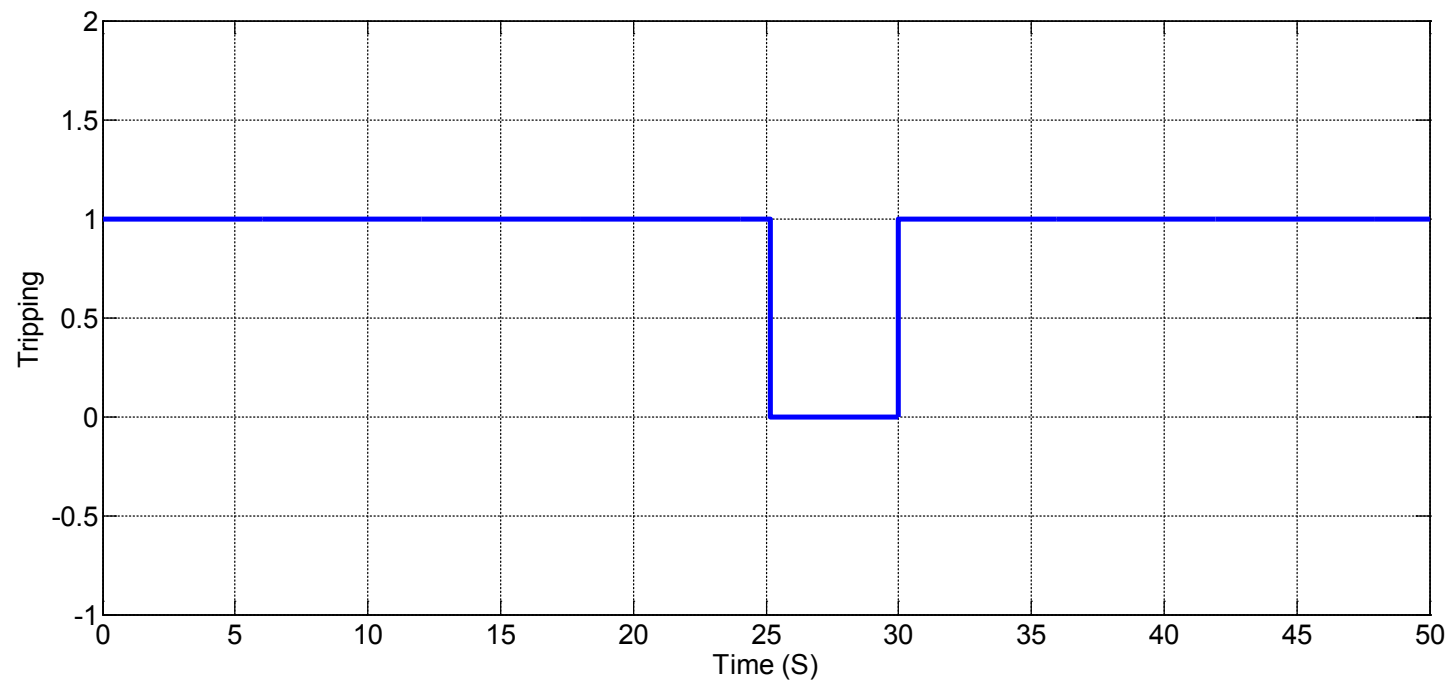

Figure 7. Relay12 Tripping during Fault

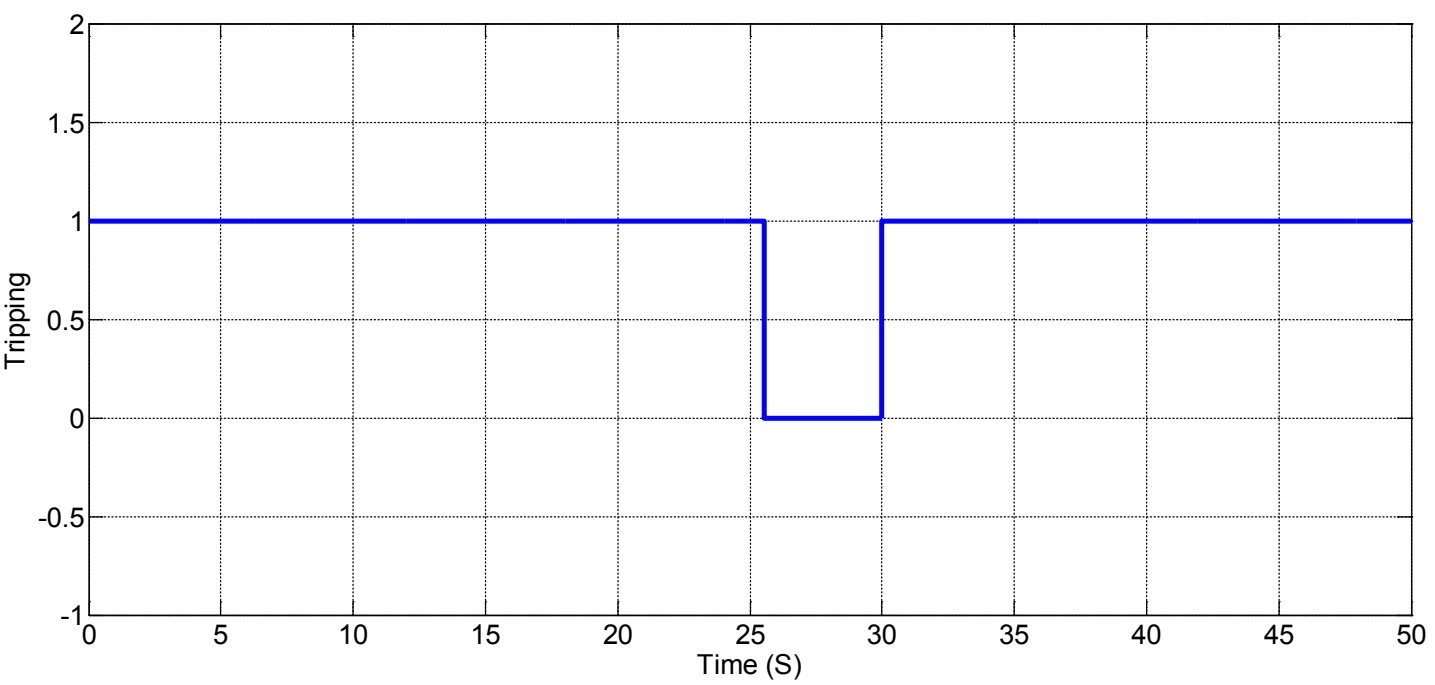

Figure 8. Relay11 Tripping during Fault

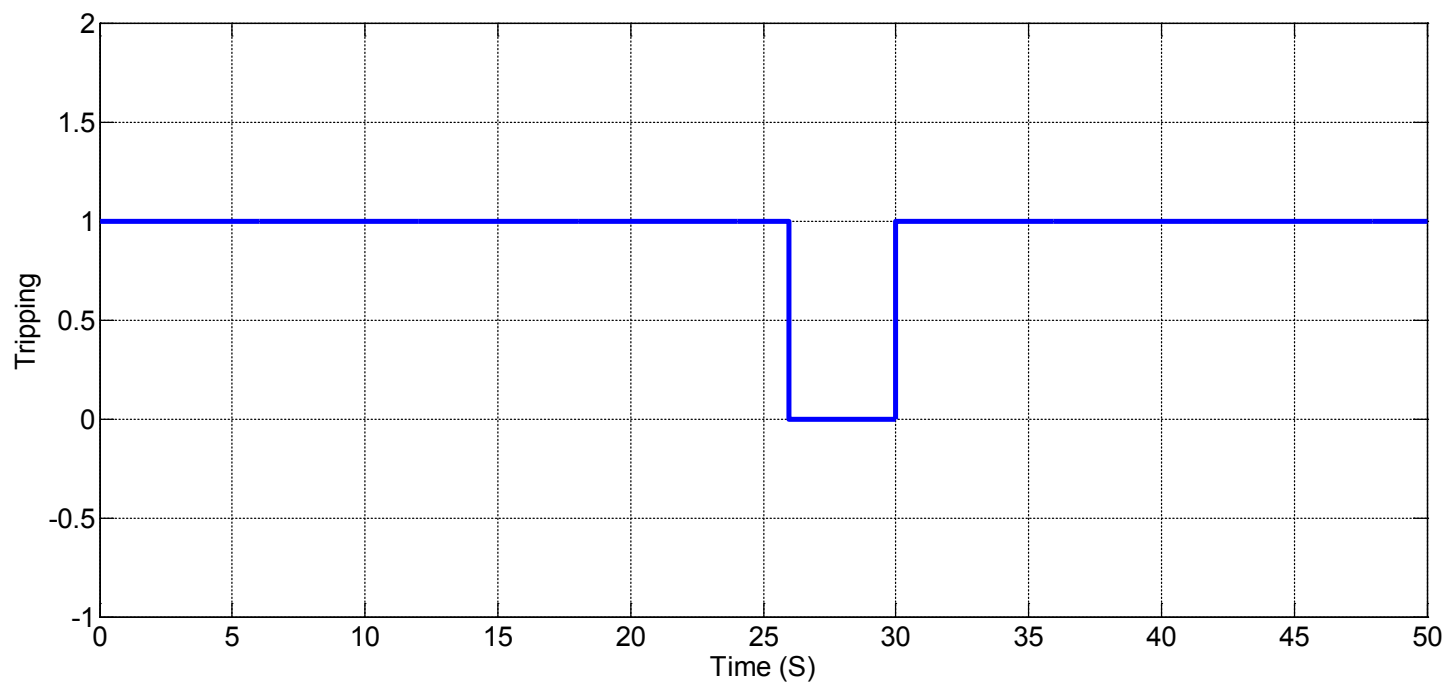

Figure 9. Relay2 Tripping during Fault 


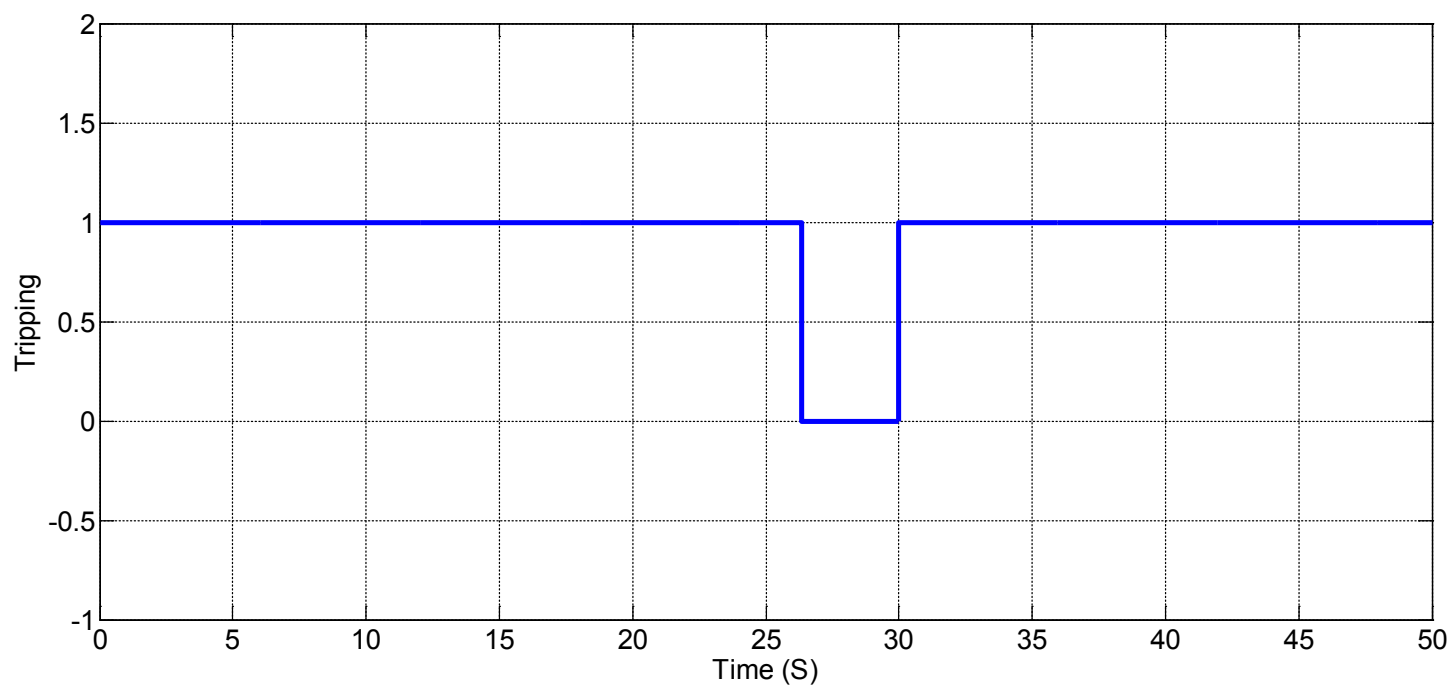

Figure 10. Relay1 Tripping during Fault

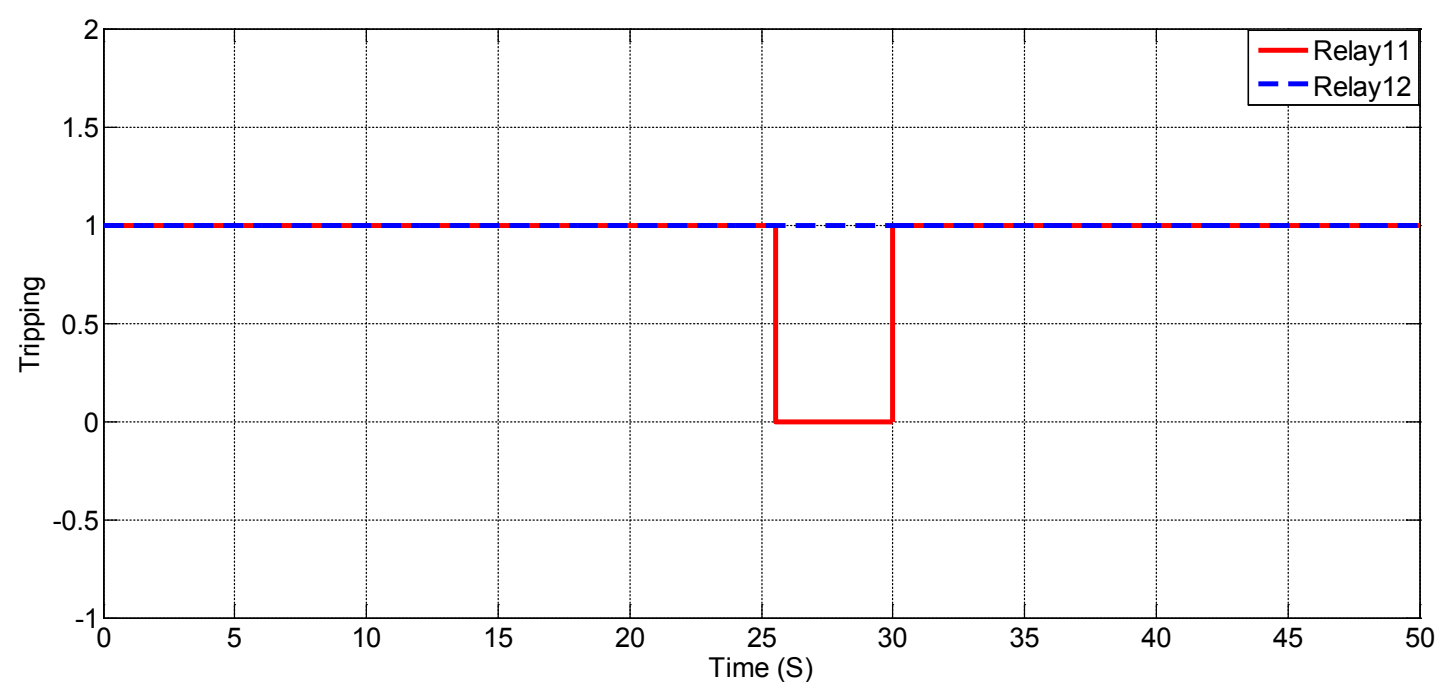

Figure 11. Relay11 Trips while Relay12 is Malfunctioning

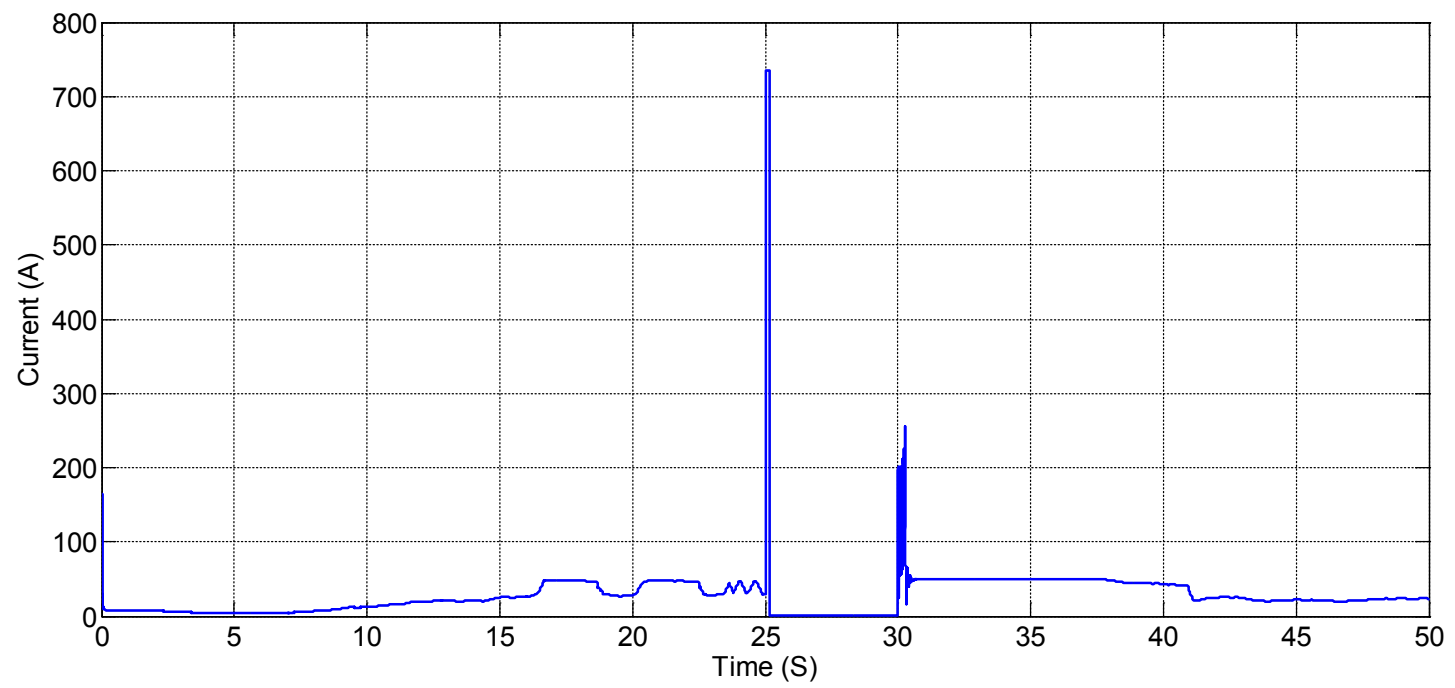

Figure 12. CB12 Operation during Fault 


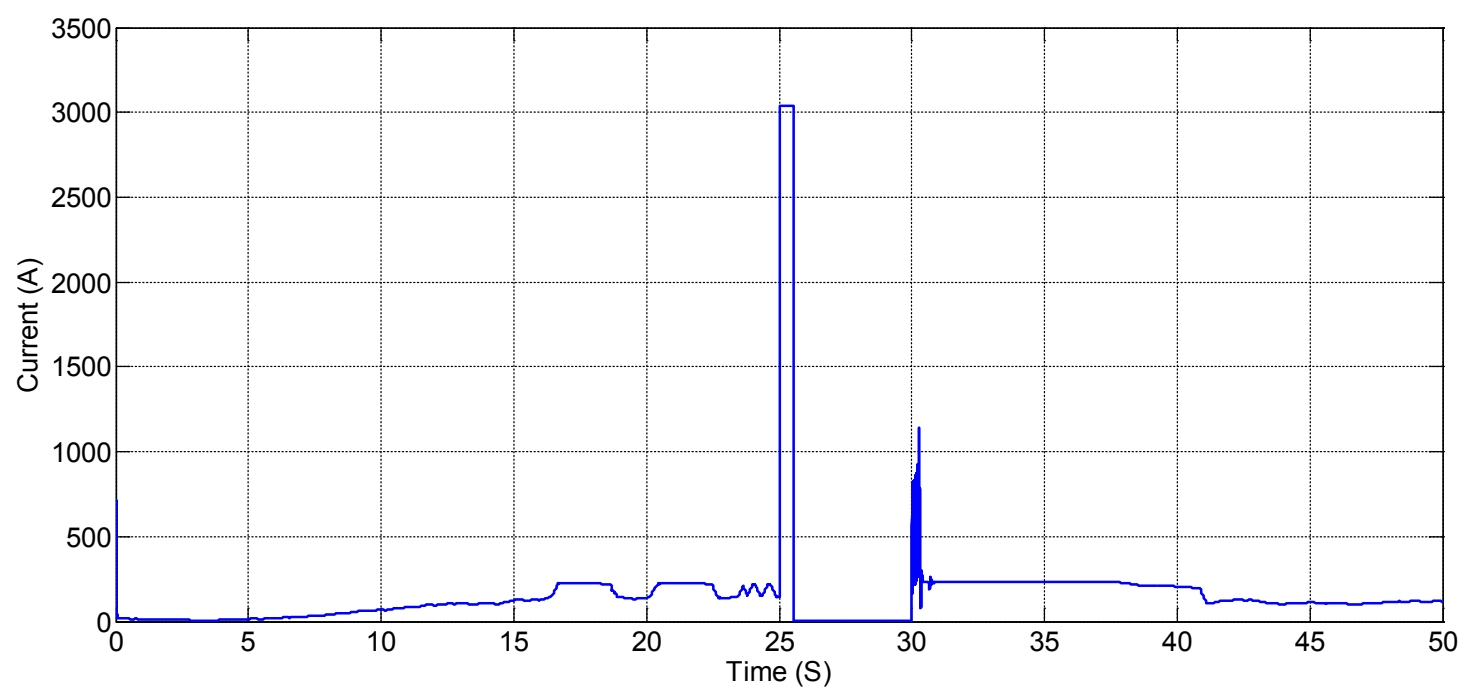

Figure 13. CB11 Operation during Fault

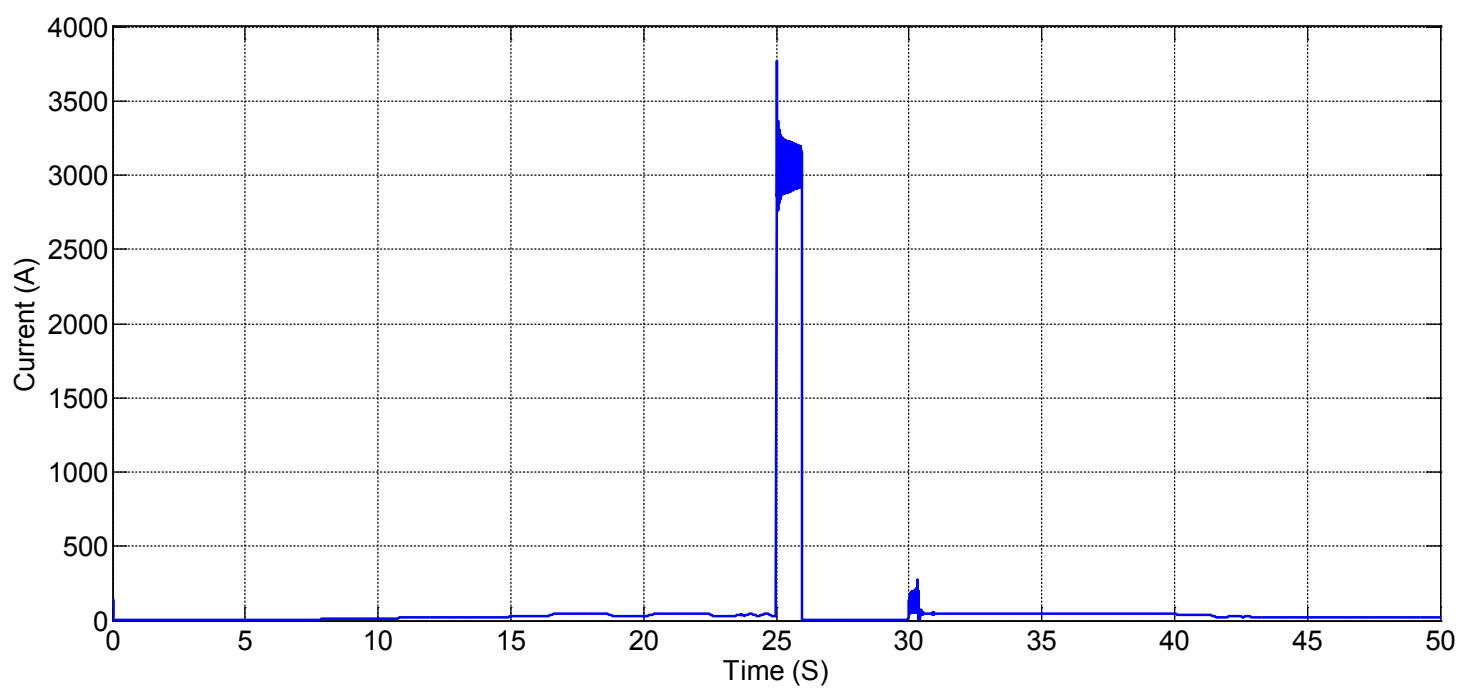

Figure 14. CB2 Operation during Fault

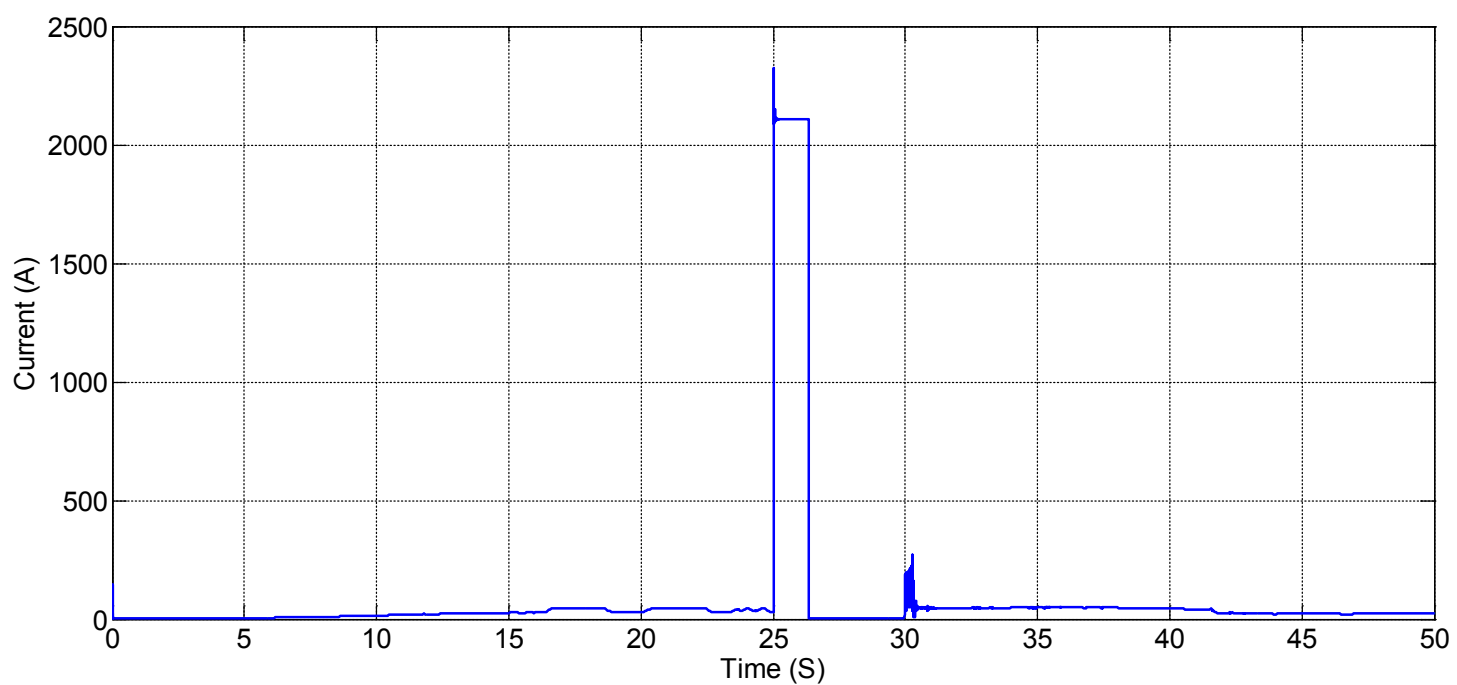

Figure 15. CB1 Operation during Fault 


\section{Conclusions}

In this paper, a comprehensive protection for wind power plants has been successfully implemented by using OCRs. Three phase fault has been imposed at each $\mathrm{CB}$ and the settings for each relay have been conducted. Moreover all of the relays have been modelled based on IEC standards in order to provide proper protection to the system, prevent the damage from fault current to the power components, provide perpetual power to the grid and contribute to superb power quality. The results have shown that OCRs can be successfully employed for wind power plants and has proved to be effective, accurate, and be considered as the best method for protection.

\section{REFERENCES}

[1] Dincer, I. (2000). Renewable energy and sustainable development: a crucial review.Renewable and Sustainable Energy Reviews, 4(2), 157-175.

[2] Mohd, A., Ortjohann, E., Schmelter, A., Hamsic, N., \& Morton, D. (2008, June). Challenges in integrating distributed energy storage systems into future smart grid. In Industrial Electronics, 2008. ISIE 2008. IEEE International Symposium on (pp. 1627-1632). IEEE.

[3] Bollen, M. H. (2000). Understanding power quality problems
(Vol. 3). New York: IEEE press.

[4] Gatta, F. M., Iliceto, F., Lauria, S., \& Masato, P. (2003, June). Modelling and Computer Simulation of Dispersed Generation in Distribution Networks. Measures to prevent disconnection during system disturbances. In Power Tech Conference Proceedings, 2003 IEEE Bologna (Vol. 3, pp. 10-pp). IEEE.

[5] Singh, M., Panigrahi, B. K., Abhyankar, A. R., \& Das, S. (2013). Optimal coordination of directional over-current relays using informative differential evolution algorithm. Journal of Computational Science.

[6] Birla, D., Maheshwari, R. P., \& Gupta, H. O. (2005). Time-Overcurrent Relay Coordination: A.

[7] Chen, C. R., Lee, C. H., \& Chang, C. J. (2013). Optimal overcurrent relay coordination in power distribution system using a new approach. International Journal of Electrical Power \& Energy Systems, 45(1), 217-222.

[8] Lee, H. J., Son, G., \& Park, J. W. (2011). Study on wind-turbine generator system sizing considering voltage regulation and overcurrent relay coordination. Power Systems, IEEE Transactions on, 26(3), 1283-1293.

[9] Hussain, M. H., Rahim, S. R. A., \& Musirin, I. (2013). Optimal Overcurrent Relay Coordination: A Review. Procedia Engineering, 53, 332-336.

[10] RAZA, S., MAHMOOD, T., \& BUKHARI, S. (2014). OPTIMUM OVERCURRENT RELAY COORDINATION: A REVIEW. Nucleus, 51(1), 37-49.

[11] Muhamad Hatta, H., Rafidah, S., \& Ismail, M. (2012). Optimal overcurrent relay coordination: a review 